sondern sie muß selbst im Menschen der allernächsten Umgebung ein ethnologisches Objekt sehen, aus welchem in unablässiger Bemühung durch direkte Beobachtung und Befragung ein reiches und durch seine Zuverlässigkeit und Kontrollierbarkeit besonders wertvolles Material zu gewinnen ist, das erst das richtige Verständnis fremdländischer Erscheinungen vermittelt.

Küsnacht bei Zürich, 1. Mai 1894.

\title{
Otto Stoll.
}

\section{Vorwort zur zweiten Auflage.}

Wenn auch Grundplan und Grundgedanke des Buches dieselben geblieben sind, wie bei der ersten Auflage, so haben bei der vorliegenden zweiten Auflage doch eine Reihe von Änderungen, die, wie ich hoffe, Verbesserungen sind, Platz gegriffen. Nicht nur sind mehrere, für das Verständnis der suggestiven Wirkungen auf dem Gebiete der Völkerpsychologie sehr wichtige Partien ganz neu hinzugekommen, wie z. B. der Abschnitt über die französische Revolution, sondern einzelne Tatsachengruppen sind gegenüber der früheren Auflage auch in dem Sinne umgearbeitet worden, daß die geschilderten psychischen Erscheinungen eingehend analysiert wurden, um das suggestive Element klarer hervortreten zu lassen. Ich habe damit einem mir von befreundeter Seite mehrfach geäußerten Wunsche Rechnung zu tragen versucht. Von verschiedener Seite war mir auch darüber geklagt worden, da $B$ die erste Auflage die Zitate aus fremdsprachigen Werken in der Originalsprache brachte. Ich habe daher diesmal alle fremdsprachigen Zitate entweder selbst übersetzt oder, wo nötig, deutschen Übersetzungen entnommen, die im Text oder im Literaturverzeichnis namhaft gemacht sind. Ich hoffte auch damit die Lektüre des Buches leichter und flüssiger und die Verständlichkeit allgemeiner zu machen, als es bei der häufigen Unterbrechung des Textes durch fremdsprachige Zitate möglich war. 
In einem Buche, das, wie das vorliegende, Fragen der Völkerpsychologie und der Völkerkunde behandelt, kann selbstverständlich auf die Grundbegriffe der Individualpsychologie nicht eingetreten werden. Den Leser, der darüber sich kurz zu orientieren wünscht, verweise ich auf das soeben erschienene, kleine populäre Werk von Prof. Dr. A. Forel, Hygiene der Nerven und des Geistes im gesunden und kranken Zustande (Stuttgart, E. H. Moritz, 1904).

Den Kollegen und Freunden, die mich wiederum durch Beibringung instruktiven Beobachtungsmaterials oder durch literarische Nachweise unterstützt haben, spreche ich dafür meinen verbindlichen Dank aus.

$\mathrm{Zu}$ besonderem Danke bin ich auch dem Herrn Verleger verpflichtet, der mir nicht nur mit gröBter Liberalität betreffend den Umfang und Inhalt des Buches völlig freie Hand lieB, sondern auch während der ganzen Zeit des Druckes dem Buche ein wohlwollendes Interesse widmete.

Zürich, den 18. September 1903. 